\title{
Building the Web Interactive Study Environment: Mainstreaming online teaching and learning at the University of Western Sydney
}

\author{
Stephen Sheely \\ University of Sydney \\ Deborah Veness and Lynnae Rankine \\ University of Western Sydney
}

\begin{abstract}
The Web Interactive Study Environment or WISE was developed from 1998-2000 at UWS Hawkesbury to address the issues that have arisen in moving online teaching from the innovative to the mainstream. The principles underlying WISE are drawn from a number of educational disciplines including distance education, tertiary education and academic development. Its objective is to influence not only academic practice within the institution but also the ongoing dialogue concerning flexible and online learning.

Ownership of the process is dispersed throughout the organisation. The WISE team is involved in a wide ranging consultative process which includes virtually every sector of the university community. The result is a constantly evolving environment reliant as much on communication, negotiation and consensus as on hardware and software.
\end{abstract}

\section{Introduction}

Until recently, the adoption of educational technology (particularly for online teaching and learning) has been a haphazard affair relying on the individual efforts of scattered enthusiasts (Housego 1998, Taylor et al 1998). This has led to terms like flexible learning and online learning being used to describe a multitude of activities with highly variable success rates (Alexander et al 1998, Nunan 1996). It has also led to problems with the longevity and dissemination of innovations, because many exciting advances have been tied to those particular individuals who developed them and have not spread far, either in time or space, from their originators. 
However, a number of recent trends are driving a significant shift in focus from the individual level to the institutional. Notable amongst these has been the development of commercial software packages combining course development and maintenance tools (WebCT, Blackboard, Topclass, etc). The question is no longer can we build an institutional learning environment on the web, but how do we do it? How do we use these packages most effectively? How do we integrate them into existing systems? How do we support academics to make most effective use of the tools that are available?

Many universities are still leaving it to individual academics to create and manage their own environments (Fox et al 1998). Many institutions that are building centralised web support systems are concentrating on the delivery aspect of the process, constructing robust and reliable hardware and software systems for academics to use (Fox 1999, Salter \& Hansen 1999) investing very little in training or supporting staff. Creating a system and then leaving academic staff to get on with it is not enough. If there is to be widespread and effective uptake of these tools they must be embedded in the mainstream of academic activity (Housego 1998, Geoghegan 1996). Teaching academics must be supported and encouraged in entering the online environment and their activities acknowledged and rewarded (Hansen \& Deshpande 1999). At UWS Hawkesbury this mainstreaming process is being achieved through the development of the Hawkesbury Web Interactive Study Environment or Hawkesbury WISE. What follows is an attempt to explore the development and distinctive features of WISE, through the trends which have driven it, the issues which have shaped it, and the guiding principles which underlie its current form.

The trends encouraging an institutional approach to online teaching and learning are numerous and varied but nonetheless compelling. Many of these trends are grounded in perceptions about the nature of flexible learning, and educational technology or the future of higher education. There has been some debate in the literature (Cunningham 1998, Kirkpatrick 1999, Holton 1997, Sims 1998) about the accuracy of these perceptions but that is not at issue here. It is the trends that are driving the change and they are real regardless of the validity of the perceptions underlying them.

\section{Trends}

Diminished resources

More than any other factor in the tertiary sector at the moment the demand to do "more with less" is shaping policy within individual 
institutions as well as the sector as a whole (Marginson 1998, Thomas 1998, Coaldrake \& Stedman 1999). This demand is driven primarily by cuts in funding from government sources, forcing universities to seek alternative funding or to reduce expenditure in some fashion. This push for economy drives universities to move into online teaching as online teaching is seen, particularly by administrators, as a way to cut costs (Ryan 1999). It also drives universities to move into online teaching in a particular fashion.

In times of economic restraint it is considered preferable to work at an institutional level. Working at an institutional level allows for economies of scale and a reduction in duplication of effort across the institution. Buying in software becomes the favoured option as it is seen as less expensive than building it in house and allows academics to remain focussed on their core activities of teaching and research.

Increasingly sophisticated cheap and widely available technology

Buying in software assumes the availability of appropriate, reasonablypriced software. Four years ago this would not have been a safe assumption. However, in the last few years packages (Frontpage, Dreamweaver, etc) have appeared which allow authoring of websites without knowledge of HTML; other courseware packages such as WebCT and Blackboard provide the Java applets and other tools necessary to build effective interactive study environments and link them to student administration systems. Proliferation of cheap effective web authoring tools has been paralleled by the development of cheap powerful home computers and an accompanying boom in domestic web access.

\section{Accountability}

Recent pressures on higher education which culminated in the DETYA report "Learning for Life" (West 1998), have led to an increasing demand for accountability in the sector. This demand has been fuelled by the rise of performance indicators such as the Graduate Destinations Survey and the accompanying CEQ (Andrews et al 1997). With teaching under the microscope, universities have become acutely aware of the potential for damage to their reputations by bad teaching, particularly when it is preserved in a written medium such as the web and can be scrutinised at will.

Flexible and lifelong learning

Now that "flexible and lifelong learning" have been officially mandated as the directions for tertiary education (West 1998) universities are required to target a diverse range of students using a broad spectrum of 
strategies. Exact definitions of flexible learning remain elusive (Lundin 1998, Kirkpatrick 1998). However, in some circles at least, it is seen as being synonymous with online teaching and learning (West 1999, Kirkpatrick 1998, Fox 1999) and as such is perceived as the "silver bullet" (Ryan 1999) which will allow universities to overcome their funding shortfalls.

\section{Competition}

There is a strong belief in some quarters that education is about to become a global enterprise and that Australian universities will not survive if they do not to gear up to compete with foreign universities in both local and international markets. Online teaching and learning is seen as an integral part of this (Bagdon 1999, Flew 1999).

\section{It is expected}

There is a fear that as computers and the world wide web infiltrate more and more aspects of our lives any enterprise which doesn't employ them will be perceived as outdated and irrelevant (Fox 1999, Ryan 1999). In particular, there is anxiety in the tertiary sector that as online teaching and learning become more prevalent in secondary schools there will be an increased expectation for them to be used in the at university (Thomas 1999). There is also a perception that the web has become an integral feature of the workplace and it is therefore expected that university graduates will have learnt how to use this technology.

Everybody is doing it

A movement like the current push toward online teaching and learning gains its own momentum and can become self sustaining. As more universities move into online teaching, those that do not risk being perceived as inadequate. This may lead to some moving into online teaching simply to "keep up".

\section{Genesis}

In 1997, a group of academics, and academic development and information technology staff came together as an informal working party at UWS Hawkesbury. They applied for and received a small internal grant to initiate what became known as the WebShell Project.

The Project was motivated by a concern that a devolved approach to Webbased teaching development would lead to piecemeal, costly, and lesseffective results, and might even have a damaging impact on the image of 
the University. The Project aimed to concentrate and coordinate resources to develop an infrastructure in support of Web-based teaching and learning initiatives within UWS Hawkesbury's academic programs. As the WebShell group consulted with staff throughout UWS Hawkesbury, a number of issues emerged regarding teaching and learning online.

\section{Issues}

\section{Quality Assurance}

The act of moving teaching online changes the private pursuit of face-toface teaching into a public, documented activity. It creates a greater reliance on outside influences - technical support, remote sites, online tools. If something goes wrong it is there for all to see, labelled as a product of the university concerned. Consequently, quality assurance becomes an institutional priority, requiring a process of review and assessment of online learning sites. This is sometimes seen as an intrusion by external agents into the previously private experience of teaching. Balancing the resistance to this intrusion against the need for monitoring is a major issue.

Web teaching is essentially different

Teaching on the web is a fundamentally different activity to traditional teaching. All communication is written and mediated. Teachers and learners are often widely separated in time and space. Interactions are delayed and less spontaneous. In this sense, online teaching shares many features with distance education. However, there are some crucial differences. The degree of interactivity made possible by the web and the possibility of non-sequential and non-linear navigation of learning materials means that while distance education principles may validly inform the development of web teaching strategies they cannot be adopted en masse or indiscriminately.

Web teaching is essentially the same

While the medium and the environment change dramatically in the move online, there are certain fundamentals of teaching which remain constant. The most useful of these are the principles concerning students' willingness to adopt a deep or surface approach to their studies and the impact this has on whether they learn meaningfully or not. The literature (Ramsden 1992) suggests that key factors in the learning environment (such as workload or relevance) will encourage students to take certain approaches to their learning and enhance their chances of achieving desired outcomes. 
Teaching online is not an individual effort

Teaching online requires a greater range of skills and a much higher degree of external support than has previously been the case in university teaching. The result is that maintaining teaching as an isolated endeavour by single individuals is becoming less and less tenable. Ideally, teaching online will be a collective activity with faculty staff playing the roles of discipline experts, supported by people with computing, technical, and educational expertise.

\section{Workload}

Flexible teaching and online teaching are often presented (Bacsich 1999, Ryan 1999) as ways of reducing workload or teaching time. Yet anecdotal evidence (Bacsich 1999, Porter and Corduroy 1998) suggests that unless carefully monitored, moving subjects online can lead to an increase in workload for the staff involved

The need to make it commonplace (and influence the discourse)

Online teaching and learning is still perceived as novel, radical, and in some sense, too hard by most academics. Kirkpatrick (1998) points out that certain discourses become privileged within institutional discussions of concepts such as flexible learning. This can shape activities within the institution and influence the allocation of resources, the degree of staff participation, and the expectations of anyone who becomes involved. If online teaching and learning is to be successfully adopted - to become commonplace - institutional discourse must reflect the intentions, processes, and structures supporting it.

\section{Distribution of expertise}

Any innovation requires a certain level of expertise. The issue is how should this expertise be distributed? Should it be centralised at an institution level, franchised through the development of local experts, or dispersed by training the entire staff of the institution? Each possibility brings problems and benefits. Centralising expertise may lead to alienation of the majority the staff and the death of innovation, but it does allow for a high degree of expertise and rapid response to problems. Dispersing creates an increased sense of ownership and a greater likelihood of academic staff using the innovation, but it raises the issue of quality assurance. Franchising, like all compromises may provide the best of both worlds but runs the risk of providing the worst of both worlds. It requires expenditure of time and energy to train local staff who may still refer most queries back to the central unit. 


\section{The model}

\section{Evolution}

As WISE evolved it became obvious that the structures involved could be neither permanent nor fixed. We started to say "it's a process not a product" it is therefore is not defined by mechanisms, structures or rules but by the principles that underpin it and the approaches that it encourages. This paper describes these principles, and how they have been implemented in this current incarnation.

\section{Publishing Model}

Traditional teaching is verbal, ephemeral, and individualistic. Online teaching is written, semi-permanent and involves a range of people. In promoting effective use of the medium by teaching staff it has been necessary to invoke a different model. Viewing the construction of online learning environments as a publishing exercise has proved effective in promoting the need for a different approach. Acknowledging that releasing online teaching materials to students is, in essence, publishing reinforces with academics the need for care in producing materials which will have a life span that will extend well past that enjoyed by casual utterances in the classroom. It emphasises the difficulties in preparing material which must stand alone and where corrections and additions cannot be made on the run. Further, it legitimises the role of others involved in the construction process.

\section{Static/dynamic dichotomy}

The model differentiates strongly between the static and dynamic elements in an online learning site. Static material was defined as material which will not change after publication - information to be transmitted. It is usually text, but may include animations, video, audio, and a range of online tools such as quizzes.

Dynamic elements are those which allow communication, primarily bulletin boards and chat rooms. Some elements such as the calendar, which have time release parameters, are treated as static. Other elements, such as glossaries, which may require additions as the subject is delivered are regarded as static as at the point of publication they ought to be complete. This dichotomy is explained to students so they know which aspects of a subject change regularly and which remain constant.

This approach may appear at odds with what some see as the major benefit of online teaching and learning - the ability for academics to 
change and update material (Smith 1999). However we feel that constant updating of material damages rather than enhances the students' learning experience. It removes most of the flexibility that online learning should provide. If students are to move through material in their own way and in their own time they must be able to trust that the material is not going to change.

Similarly, students cannot set their own study pace if they are waiting for the next section to be uploaded. Frequently changing materials on a site or building it week by week to ensure its currency places control of what is learned and how and when it is learned back in the hands of the academic. While that may be comforting for them, it is anything but flexible for their students. This is not to say we are advocating the production of shovelware (Fox 1999). In fact the WISE system strongly encourages academics to keep the static elements of their environment to a minimum and to do most of their online teaching through the communication tools.

Encourage the appropriate use of technology and the use of appropriate technologies

The WISE model encourages staff to think of flexible learning as more than teaching online. The model situates WISE within the Flexible Learning Unit and maintains strong and obvious links between the online teaching and learning agenda and broader flexible learning imperatives. This encourages staff to identify first their desired learning outcomes, then use a mix of media to achieve these outcomes.

Eliminate unnecessary choice

WISE supports a limited number of software and hardware options for those interested in online teaching. WISE also strongly influences staff in their initial choice of tools by providing subject templates. We contend that certain choices are unimportant, particularly given that there is so little difference between options (Firdyiwek 1999) and that resources are better directed toward training and advice for academic staff than the endless search for perfect software.

Stepwise development of subjects

As part of the publishing process, WISE learning packages pass through a series of precincts on the server. DEVELOPMENT, where staff have free reign to create whatever they want and students have no access. TEST, where editors and resource developers check for problems. LIVE, where learning resources are released and available for use by students (Rankine et al 2000). 
The project remains with the academic who initiates it

FLU and WISE are support units. The academic(s) involved retain control and remain core to the process. The quality assurance process is managed as a support mechanism at a subject level not a judgemental one at an institutional level.

\section{Staff development}

The model has a strong staff development focus which concentrates on educating staff in the principles of online teaching. As numerous authors (Alexander et al 1998, Laurillard 1993) have pointed out there is nothing intrinsically educational about dealing with materials on the web. To facilitate effective teaching, the team has developed a pedagogy of online learning: it is this that forms the basis of the majority of the staff development work we do. WISE is set up to provide staff with enduring teaching skills for the online environment rather than rapidly outdated training in a particular software.

Develop an educational community

Much of the staff development work in this model centres on weekly "writers' group" meetings. These meetings are for all staff involved in constructing educational websites. They are non-compulsory sessions at which staff can ask questions, see demonstrations of new tools or new teaching strategies or simply build their sites in a collaborative environment. These meetings provide a regular opportunity for solving problems and a supportive work environment. Most importantly, this group helps develop support networks across faculties and departments within the institution.

Centralise coordination but not expertise

While WISE relies on central coordination of all its activities it is essential that expertise associated with online teaching and learning does not become (be perceived to become) the province of a single central unit. We have attempted to diffuse expertise throughout the organisation to avoid this. We have tried to minimise the need for expertise by using user friendly interfaces and simple-to-use software wherever possible.

\section{Summary}

The current WISE model provides for an online resource for every subject, created from a basic template. These proto-subjects are held in the DEVELOPMENT precinct on the WISE server. Staff wishing to develop the online environments for their subjects are supported by a range of staff with distance education, academic development, web, and editorial skills. They are encouraged to attend a web authors' group where they 
can share their ideas, and questions with other academics from different groups across the university.

When academics have finished developing the learning package for their subject it goes through a TEST regime. Any problems are referred back to them to be fixed in consultation with web support staff. When the site proves robust enough to survive the test regime it is moved into the LIVE precinct, where it can be accessed by students. At this point a number of the online elements in the resource become static, remaining unchanged for the duration of that edition. Other elements remain dynamic, allowing additions to be made to the site and promoting communication between students and staff. Meanwhile the next edition of the learning resource remains in DEVELOPMENT being revised, updated, and modified in preparation for publication the next time the subject is offered.

\section{Intended outcomes}

The WISE team's major intended outcome is the production of quality online learning environments for students at UWS Hawkesbury. We believe that this model will help us achieve this outcome for the following reasons.

It focuses attention on teaching and learning

Every aspect of the model is geared toward making the technical details of online teaching and learning as automatic and transparent as possible so that academics can focus on the real issue of building effective learning environments. We have adopted the publication model so staff members have a clear guide to the nature of teaching online and the time needed to produce effective materials. We have built basic subject templates for all subjects so that staff have a head start in creating online environments. We have housed these in the DEVELOPMENT precinct so that staff can work on them, experimenting and making mistakes without worrying about the impact on their students.

It balances issues of quality against issues of ownership

There is an apparent tension between the desire for staff to retain ownership of their own teaching environments and the need for quality assurance at an institutional level. Staff members who are left alone to create sites without institutional input may create environments which do not work, are difficult to navigate or look at, or in some other way create difficulties for students. The traditional approach of distance education centres has been to isolate the academic from the whole production 
process, taking raw content from academics and putting it through editing, desktop publishing and printing without further consultation. This has resulted in academics losing ownership of the finished product and often being less than enthusiastic about it. WISE deals with this issue by maintaining the centrality of the academic "author" while providing support staff to help create the sites.

\section{It formalises software and hardware maintenance}

There are many examples in the literature of the frustration that can occur for both staff and students when technical difficulties impede online teaching and learning activities (Porter et al 1998). It is widely accepted that the best way to overcome this problem is to use the existing IT skills of the organisation to maintain and service the core hardware of the learning environment (Housego 1998). Using a server running only the educational software housed in the central IT area removes many of the difficulties that can occur when running educational software off desktop hard drives.

\section{It refocusses the discussion}

All of the above works at two levels: it impacts directly on the teaching practice of those academics moving to the online environment; it also impacts on the rhetoric surrounding online teaching and learning. As long as teaching and learning online or with computers is perceived as novel then it is the computer that will be seen as the innovation not its use. Making online teaching and learning a commonplace refocusses discussions regarding computers in learning on how best to use the medium not on the medium itself.

It takes advantage of permissible needs

One of the major issues in academic development is permissible needs (Andresen pers comm). Most academics are reluctant to approach academic developers for help with their teaching because to do so reflects a need it is not acceptable to admit. Online teaching and learning however, is a relatively new field and it is culturally acceptable to find it difficult. Consequently, many academics who would not normally seek help regarding teaching issues are happy to approach one of the WISE team to ask for help in learning how to teach online.

This provides a unique opportunity to enter into a dialogue with these staff about all aspects of teaching and learning and course and subject design including but not limited to online teaching and learning. Ehrmann (1998) describes the case of a lecturer who was meant to be testing a particular software by converting to online teaching. In 
preparation for this he analysed the purpose and structure of his subject. When the software in question wasn't ready in time he used this analysis to restructure his face to face teaching and received significantly improved teaching evaluations as a consequence. This is possibly how online teaching and learning will make its biggest impact on the quality of teaching and learning - not through any benefits inherent in the technology but because it inspires this willingness to go back to first principles and review and revise.

It attempts to prevent an escalation in workload

A number of writers (Porter et al 1998, Ryan 1999) have commented on the tendency for workloads to escalate for staff newly involved in online teaching and learning. WISE circumvents this at a number of levels, firstly by providing staff with a ready made system. Staff members do not have to spend time acquiring and maintaining software or hardware or even setting up a subject. Secondly, we provide staff with a (relatively) user friendly interface to use to develop their learning package, saving them the need to create the subject using HTML (or indeed the need to learn HTML to begin with). Thirdly, by using the publication model, we diminish the expectation that staff will work constantly on their sites, staying one jump ahead of their students.

\section{Evaluation}

How do we know if we have succeeded?

At the time of writing the system has been in place for only six months as a prototype and is about to commence its first year of full implementation, so finding even preliminary answers to this question is difficult. In some ways, however, we already know the answers: either "not yet", or "yes - for now". "Flexible / online learning" itself is in flux, the tertiary sector is in a period of upheaval, the technology is constantly evolving. To cope with this the WISE system remains adaptable. We are constantly monitoring system performance, online student feedback surveys are a part of every template, and the web authors group provide us with ongoing feedback. We are accumulating statistics on staff uptake and student usage. None of this will be used in a judgemental sense to pass final verdict on WISE. It is all being gathered to help revise and adapt to inform and direct the evolution that will inevitably occur as WISE changes to keep pace with a changing environment. 
At another level we have succeeded as we have developed a set of guiding principles which will allow us to make informed decisions on the basis of any feedback we get. So while it may be early days yet, in one sense it always will be.

\section{Conclusions}

The first conclusion is that it can be done. There has been much discussion in the literature about what such a system would and could look like (Fox 1999, McLendon et al 1999, Sims 1997) what characteristics it should have, what principles should guide it and what issues it should address. With WISE we have taken these conjectures and put them into practice.

In doing so we have learnt much about such systems. We have learnt that they cannot be rigid and permanent. The principles on which they are based are stable but the way these principles are implemented will change as the tertiary environment changes, as staff change and as students change. Perversely, change has become the one constant of the tertiary sector (Taylor et al 1996).

We have learnt that in building such a system in such an environment there are going to be tensions. Conflicting demands will arise and delicate balances will need to be maintained. We have come to believe that many of these conflicts and much of this tension arise because online teaching and learning serves as a nexus for the convergence of distance education and class room teaching. We have become convinced that in order to balance these tensions, systems such as WISE need to draw on both on campus teaching and distance education. Most of the models previously proposed draw on either one or the other and as a consequence are limited.

We have learnt more about the key role that staff development must play in any such system. In particular we have realised that a unique opportunity exists to use the impetus afforded by discussions surrounding online teaching and learning to open up broader discussions concerning teaching and learning at universities both at an individual and an institutional level. Similar opportunities exist to develop an educational community and make teaching a more collaborative venture rather than an isolated and private one.

Possibly the most important that we have learnt is that the creation and maintenance of the technical side of such a system is the easy bit. 
Acquiring and maintaining servers, choosing software, and loading and debugging it are often seen to be the crucial part of such a system. However, it is clear to us that the hardest and most rewarding work comes from the abstract elements. Consulting with staff, negotiating with other units, changing attitudes, creating a sense of ownership, developing an institutional culture in which staff can think strategically about their teaching at program and faculty level, maintaining enthusiasm and fostering creativity in a changing, challenging field.

\section{References}

Alexander, S., McKenzie, J. \& Geissinger, H. (1998). An evaluation of information technology projects for University learning. EIP, DETYA, Canberra. [Exec Summ verified 20 Mar 2001 at http:/ / www.autc.gov.au/in/in_pu_cu_ex.htm]

Andrews, L., Aungles, P., Baker, S. \& Sarris, A. (1997). Characteristics and Performance of Higher Education Institutions (A Preliminary Report). DETYA Canberra. http:/ / www.detya.gov.au/archive/highered/otherpub/heperf.pdf

Bacsich, P. \& Ash, C. (1999). The hidden cost of networked learning - the impact of a costing framework on educational practice. In Responding to Diversity. Proceedings of the 16th Annual Conference of ASCILITE, Queensland University of Technology. http: / / www.ascilite.org.au/conferences/brisbane99/papers/bacsichash.pdf

Bagdon, K. (1999). Challenges to the higher education sector from corporate or virtual providers: The US and Australian response. Keynote at Responding to Diversity, 16th Annual Conference of ASCILITE. http: / / www.ascilite.org.au/conferences/brisbane99/ papers/bagdon.pdf

Coaldrake, P. \& Stedman, L. (1999). Academic work in the twenty-first century. Occasional Paper, Higher Education Division, DETYA, Canberra, Australia. http: / / www.detya.gov.au/archive/ highered/occpaper/99H/academic.pdf

Cunningham, S. (1998). Technology and delivery: Assessing the impact of new media on 'borderless' education. Australian Universities Review, 41(1), 10-13. In: http: / / www.nteu.org.au/ services / publics / aur/a198.pdf

Ehrmann, S. (1997). How (not) to evaluate a grant funded project. http:/ / www.tltgroup.org/flashlight/ evaluate.html [verified 21 Mar 2001 at http: / / www.tltgroup.org/programs/hownot.html]

Firdyiwek, Y. (1999). Web-based courseware tools: Where is the pedagogy? Educational Technology, 39(1), 29-34.

Flew, T. (1998). Fast times at Virtual U: Digital media markets and the future of higher education in the West Report. Australian Universities Review, 41(1), 2025. In: http:/ / www.nteu.org.au/services/publics / aur/a198.pdf 
Fox, R. (1999). An examination of online learning environments in distance education. Open and Distance Learning Association of Australia Occasional Papers, No. 1.

Fox, R., Herrmann, A. \& Boyd, A. (1999). Breaking the grip of print in distance education. Collected Papers from the 14th Biennial Forum for the Open and Distance Learning Association of Australia. Deakin University and Gordon Institute of TAFE, Geelong.

Geoghegan, W. (1996). Instructional technology and the mainstream: Risks of success. Maytum Distinguished Lecture. SUNY College, Fredonia.

Hansen, S., Deshpande, Y. \& Murugesan, S. (1999) Adoption of web delivery by staff in education institutions: Issues, strategems and a pilot study. Proceedings Ausweb 99, Ballina. http: / / ausweb.scu.edu.au/aw99/papers/hansen/

Holton, R. (1997). Some myths about globalisation. In Learning and Teaching in Higher Education: Advancing International Perspectives. Special Edition Proceedings of the HERDSA Conference, Flinders University, Adelaide.

Housego, S. (1998). Changing conceptions: Support for the adoption of computer mediated communication. In Flexibility - the Next Wave. Proceedings of the 15th Annual Conference of ASCILITE, University of Wollongong, Wollongong, NSW. http: / / www.ascilite.org.au/ conferences/wollongong98/asc98pdf/housego0072.pdf

Kirkpatrick, D. (1998). Representations of flexible learning: Implications for academic practice. Proceedings of the 20th Annual Conference HERDSA, Auckland, New Zealand. [verified 10 Apr 2001] http: / / www.auckland.ac.nz/cpd/HERDSA/HTML/TchLearn/ / KIRKPAT.HTM

Laurillard, D. (1993). Rethinking University Teaching: A Framework for the Effective Use of Educational Technology. Routledge, London.

Lundin, R. (1998). Flexible delivery of continuing professional education: Models, issues and trends. [verified 21 Mar 2001] http:/ / www.usask.ca/ dlc/Context.html

Marginson, S. (1998). Higher education after the election: It will get worse before it gets better. Australian Universities Review, 41(1), 2-4. In:

http: / / www.nteu.org.au/services/ publics/aur/a198.pdf

McLendon, E. \& Cronk, P. (1999). Managing online programs: Is a paradigm shift needed? Collected Papers from the 14th Biennial Forum for the Open and Distance Learning Association of Australia. Deakin University and Gordon Institute of TAFE, Geelong, Victoria.

Nunan, T. (1996). Flexible learning - what is it and why is it part of current educational debate? Paper presented at the Annual Conference of the Higher Education Research and Development Society of Australasia, July, Perth, WA.

Porter, A. \& Corduroy, R. (1998). "There is only two weeks to go - can I get my subject on the web? A case study. In Flexibility - the Next Wave. Proceedings of 
the 15th Annual Conference of ASCILITE, University of Wollongong, Wollongong, NSW. http:/ / www.ascilite.org.au/conferences/wollongong98/asc98pdf/portercorderoy0007.pdf

Ramsden, P. (1992). Learning to Teach in Higher Education. Routledge, London.

Rankine, L., Veness, D. \& Sheely, S. (2000). Managing quality assurance, technical support and online infrastructure in a central support unit: The WISE experience. Proceedings of the WebCT2000 Conference, UGA, Athens, Georgia. https: / / webct.uga.edu/UGAWEB2K/ student_pres/Group57/index.html [verified 21 Mar 2001, restricted, for access see WebCT 2000 Conference Papers, http: / / www.webct2000.org/conferencepapers.html]

Ryan, Y. (1998). Time and tide: Teaching and learning online. Australian Universities' Review, 41(1), 14-19. In:

http: / / www.nteu.org.au/services / publics/ aur/a198.pdf

Salter, G. \& Hansen, S. (1999). Modelling new skills for online teaching. In Responding to Diversity. Proceedings of the 16th Annual Conference of ASCILITE. Queensland University of Technology, Brisbane. http:/ / www.ascilite.org.au/conferences/brisbane99/ papers/salterhansen.pdf

Sims, R. (1997). Interactive learning as an "emerging" technology: A reassessment of instructional design strategies. Australian Journal of Educational Technology, 13(1), 68-84. http:/ / www.ascilite.org.au/ajet/ajet13/ sims.html

Smith, J. (1999). Implications of online teaching for traditional distance education providers. Open and Distance Learning Association of Australia, Occasional Papers, No. 1.

Taylor, P.G., Lopez, L. \& Quadrelli, C. (1996). Flexibility, Technology and Academics' Practices: Tantalising Tales and Muddy Maps. AGPS, Canberra.

Thomas, J., Meredyth, D. \& Blackwood, L. (1998). The opposite of choice: New technologies and new markets in Australian education. Australian Universities Review, 41(1), 34-40. In:

http: / / www.nteu.org.au/ services / publics / aur/a198.pdf

West, R. (1998). Learning for Life: Final Report of the Review of Higher Education Financing and Policy. DETYA, Canberra.

http:/ / www.detya.gov.au/archive/highered/hereview / toc.htm

Stephen Sheely, Intranet Project, University of Sydney ssheely@mail.usyd.edu.au

Deborah Veness, Flexible Learning Unit, University of Western Sydney d.veness@uws.edu.au

Lynnae Rankine, Flexible Learning Unit, University of Western Sydney 1.rankine@uws.edu.au 